\title{
Effect of Alcohol Consumption and Oxidative Stress and Its Role in DNA Damage
}

\author{
Neelesh Deshpande ${ }^{1}$, Sabitha Kandi ${ }^{2}$, Manohar Muddeshwar ${ }^{1}$, K V Ramana, ${ }^{3, *}$ \\ ${ }^{1}$ Department of Biochemistry, Government Medical College, Nagpur, India \\ ${ }^{2}$ Department of Biochemistry, Chalmeda Anandarao Institute of Medical Sciences,karimnagar, India \\ ${ }^{3}$ Department of Microbiology, Prathima Institute of Medical Sciences, Karimnagar, India \\ *Corresponding author: ramana_20021@rediffmail.com
}

Received December 14, 2013; Revised January 05, 2014; Accepted January 17, 2014

\begin{abstract}
Oxidative stress has been increasingly implicated in different stages of liver cirrhosis and has been found responsible for DNA damage. Alcohol consumption and oxidative stress have been linked with DNA damage and progression of disease, leading to the hypothesis that chronic alcoholism causes DNA damage. The study was aimed at evaluating the relation between alcohol consumption and relative oxidative damage in different stages of liver cirrhosis. The study included two groups based on severity of cirrhosis of liver; categorized as compensated and decompensated liver cirrhotic patients based on child Pugh criteria. All decompensated cirrhotic patients in the study group had significantly higher MDA levels $(\mathrm{P}<0.001)$ associated with DNA Damage $(\mathrm{P}>0.01)$ than those with compensated cirrhotic patients and control group who were not suffering from liver cirrhosis. These results highlighted a significant higher degree of DNA damage in decompensated cirrhotic patients associated with oxidative stress as shown from greater average DNA migration in decompensated cirrhotic patients than in the compensated cirrhotic patients with low level of oxidative stress. Thus these results suggest that increase in MDA levels may be associated with pathogenesis and progression of liver cirrhosis.
\end{abstract}

Keywords: liver cirrhosis, genotoxicity, DNA damage, oxidative stress

Cite This Article: Neelesh Deshpande, Sabitha Kandi, Manohar Muddeshwar, and K V Ramana, "Effect of Alcohol Consumption and Oxidative Stress and its Role in DNA Damage." American Journal of Biomedical Research, vol. 2, no. 1 (2014): 7-10. doi: 10.12691/ajbr-2-1-2.

\section{Introduction}

Oxidative stress and free radicals play an important role in many diseases, such as anemia, malignant carcinomas and infectious diseases [1,2,3,4]. Many researchers have demonstrated that alcohol (ethanol) is a toxic substance, when consumed in excess has been found responsible for generation of oxidative stress. Chronic alcohol abuse results in a variety of pathological effects, including damage to the liver and other organs and is associated with an increased risk of certain types of cancers and results in patho-physiological conditions in various organs of the human body. The available literature also suggests that increase in oxidative stress has been linked with genotoxicity which has played instrumental role in the pathogenesis of liver related disease and fibrosis $[3,4,5,6]$.

Previous studies have confirmed that a lipid per oxidation product, (malondialdehyde) MDA stimulates directly or indirectly the lipocytes (ito cells) resulting in liver fibrosis $[7,8,9]$. Likewise, it has been suggested that chronic alcoholism may facilitate the formation of oxidative stress causing accelerated liver injury [10]. The oxidative stress so generated may affect all types of biological molecules, including DNA, lipids, proteins and carbohydrates which in turn may be responsible for processes such as mutagenesis, carcinogenesis, membrane damage, lipid per-oxidation, protein oxidation and fragmentation, as well as carbohydrate damage and liver pathogenesis $[11,12,13]$. The aim of this study was to evaluate alcohol consumption as a potential risk factor responsible for oxidative stress, playing a key role in progression of liver disease, leading to the hypothesis that chronic alcoholism causes DNA damage. Thus the objective of the present study was to evaluate the frequency and magnitude of DNA damage among adults with chronic alcoholism.

\section{Materials and Methods}

The study included eighty five patients with alcoholic cirrhosis of liver and the study subjects were divided into two groups of cirrhotic patients based on severity of disease. Subjects included were grouped as compensated and decompensated cirrhosis after clinical and laboratory investigations and control group who do not consume alcohol and are not suffering from liver cirrhosis. 35 patients were in compensated group with the mean age of $42 \pm 10$ years, while the decompensated group consisted of 50 patients with mean age of $42 \pm 8$ years having alcoholic cirrhosis of liver. 90 individuals with no history of alcohol consumption and without liver cirrhosis are 
recruited as controls in the study. Patients were obtained from gastroenterology ward of Government Medical College and Super speciality teaching hospital with proven history of liver cirrhosis on the basis of clinical, biochemical and imaging methods and endoscopic signs. The severity of the disease was evaluated according to the Child-Pugh classification [14]. Informed and written consent was obtained from each patient included and the study and was approved by institutional ethical committee.

\subsection{Exclusion Criteria}

Patients with non alcoholic cirrhosis due to Hepatitis B, Hepatitis C, Wilsons Disease, Haemochromatosis, $\alpha_{1}$ Antitrypsin Deficiency and Toxic damage to the liver were excluded. Patients taking steroids, smokers, obese persons, individuals with co-existing diseases like Diabetes mellitus (DM), cardiovascular disease (CVD), Malignancy, chronic renal failure and patients with vitamin supplementation were also excluded. Blood sample was drawn on first day of admission with no history of vitamin or antibiotic therapy.

\subsection{Lipid per-Oxidation Measurement (MDA (nmol/ml))}

The MDA was estimated by the standard method where the Serum lipid peroxide was mixed with Methyl Phenyl indole in acidified medium and after incubation for $48^{\circ} \mathrm{C}$ for 60 minutes, the resultant chromophore intensity was recorded at $586 \mathrm{~nm}$ [15].

\subsection{Alkaline Unicellular Electrophoresis}

The alkaline unicellular electrophoresis assay using blood samples was performed as described by Singh et al., 1988 [16]. The migration was calculated as the difference between length and diameter. The criterion for determining DNA damage was to follow the amounts of DNA in the tail: without DNA damage (DNA migration $\leq$ $5 \%$ ); with DNA damage (DNA migration > 5\%). Another criterion for evaluating degree of DNA damage was low degree DNA damage when cells had 5-40\% and high degree DNA damage when cells had > 40\% (Figure 1); also we evaluated the magnitude of DNA damage by number of cells by individual. In this sense, it was used two categories: low magnitude when subjects had 1-5 cells with DNA damage and high magnitude when subjects had 6 more cells with DNA damage.

\subsection{Statistical Analysis}

The continuous variables were recorded as a Mean \pm standard deviation. Statistical analysis was performed with open-epi software. The significance of difference between the various groups was calculated using the Correlation, ANOVA-f test to ascertain whether the differences between the various groups were clinically significant.

\section{Results}

\subsection{Clinical Evaluation of Study Groups}

The clinical characteristics of the study subjects had majority of cases with decompensated cirrhosis and had evidence in the form of ascites and hepatic encephalopathy, reflecting the fact that cirrhosis goes largely undetected in initial stages in our country. A few cases which came to outpatient department of Biochemistry did not show any clinical signs of ascites and hepatic encephalopathy.

\subsection{DNA Damage}

We found a DNA damage frequency of $18 \%$ in healthy adults, in contrast with $42 \%$ in compensated patients with chronic alcoholism and $73 \%$ in decompensated patients; these differences were statistically significant among healthy adults' vs cirrhotic patients $(\mathrm{P}<0.05)$. Likewise, we observed that DNA damage frequency between cirrhotic groups i.e. among compensated and decompensated cirrhosis patients was statistically significant $(\mathrm{P}<0.05)$ (Figure 1 and Table 1$)$.
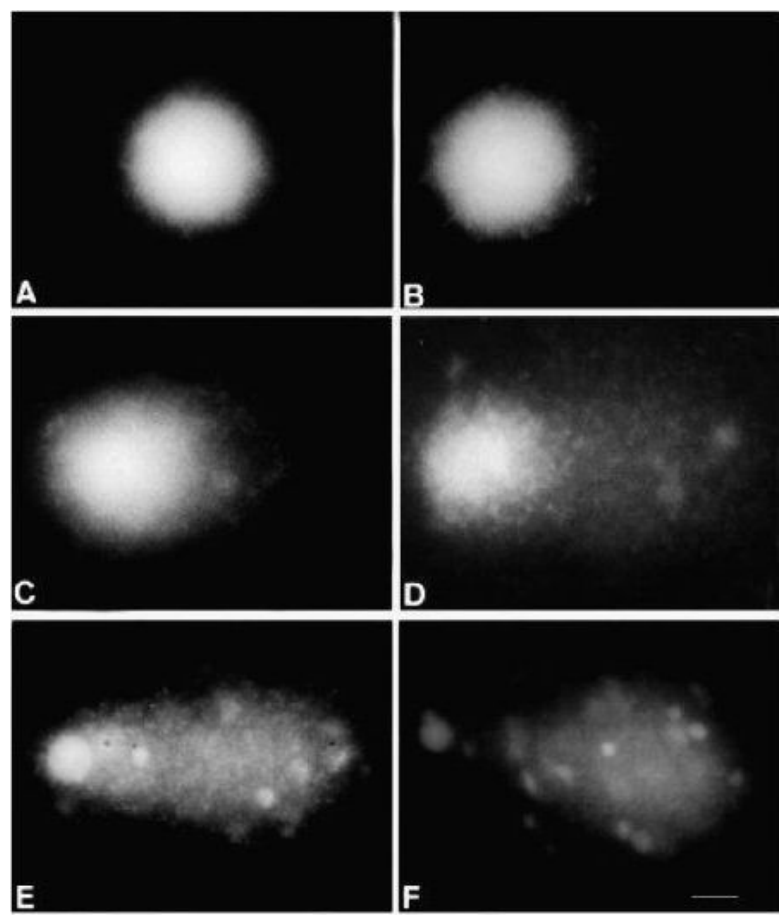

Figure 1. Images of comets (from lymphocytes), stained with ethidium bromide. A \& B Without damage; C \& D. Low-degree DNA damage when cells had 5-40\%; high-degree DNA damage when cell had $>40 \%$

Table 1. Mean values \pm SD of MDA in controls compensated cirrhotic patients and decompensated cirrhotic patients

\begin{tabular}{|c|c|c|c|}
\hline LIPID & CONTRO & COMPENSAT & DECOMPENSA \\
PEROXIDATI & LS & ED & TED \\
ON & $\mathbf{n = 9 0}$ & $\begin{array}{c}\text { CIRRHOSIS } \\
\mathbf{N}=\mathbf{3 5}\end{array}$ & $\begin{array}{c}\text { CIRRHOSIS } \\
\mathbf{n}=\mathbf{5 0}\end{array}$ \\
\hline MDA & $3.03(0.96)$ & $7.77(1.21)$ & $9.91(1.40)$ \\
\hline
\end{tabular}

Mean values \pm SD of MDA, Malondialdehyde

ANOVA-f test, $\mathrm{P}<0.001$, control vs. compensated and decompensated cirrhotic patients, Patients with compensated vs. decompensated cirrhosis, $\mathrm{P}<0.001$

\subsection{DNA Migration}

On comparing migration totals of the comet tail without taking into consideration nucleus and total migration, the decompensated cirrhotic group demonstrated an average DNA migration value that was higher than in group of compensated cirrhotic patients and the average of both cirrhotic group was significantly higher than in group of healthy adults with no liver disease $(p<0.01)$ (Table 2$)$. 
Table 2. Mean values \pm SD of DNA migration in controls compensated cirrhotic patients and decompensated cirrhotic patients

\begin{tabular}{|l|l|l|l|}
\hline $\begin{array}{l}\text { COMET } \\
\text { ASSAY }\end{array}$ & $\begin{array}{l}\text { CONTROLS } \\
\mathrm{n}=90\end{array}$ & $\begin{array}{l}\text { COMPENSATED } \\
\text { CIRRHOSIS } \\
\mathrm{n}=35\end{array}$ & $\begin{array}{l}\text { DECOMPENSAT } \\
\text { ED CIRROSIS } \\
\mathrm{n}=50\end{array}$ \\
\hline $\begin{array}{l}\text { Total } \\
\text { Migration }\end{array}$ & $48.95(6.52)$ & $36.58(8.46)$ & $78.39(17.15)$ \\
\hline comet tail & $8.86 \mu \mathrm{m} \mathrm{(2.58)}$ & $15.37 \mu \mathrm{m} \mathrm{(1.34)}$ & $57.05 \mu \mathrm{m} \mathrm{(5.22.)}$ \\
\hline
\end{tabular}

Mean values \pm SD; ANOVA-f test

Total migration: control vs. compensated and decompensated cirrhotic patients, $\mathrm{P}=0.001$. Patients with compensated vs. decompensated cirrhosis, $\mathrm{P}=0.05$

\subsection{Cell Damage Magnitude}

Table 3. DNA damage in cirrhotic by number of cells in healthy adults, compensated \& Decompensated Cirrhotic Patients

\begin{tabular}{|c|c|c|c|c|}
\hline & \multirow[t]{2}{*}{ Without Damage } & \multicolumn{3}{|c|}{ Cells with DNA Damage } \\
\hline & & $1-5$ cells & 6 and more cells & Total \\
\hline Control & 76/90(84\%) & 14/90(16\%) & 0/90(0\%) & $90 / 90(100 \%)$ \\
\hline Compensated liver cirrhosis & 10/35(29\%) & 18/35(51\%) & 7/35(20\%) & $35 / 35(100 \%)$ \\
\hline Decompensated liver cirrhosis & 9/50(18\%) & $13 / 50(26 \%)$ & $28 / 50(56 \%)$ & $50 / 50(100 \%)$ \\
\hline
\end{tabular}

Percentage of subjects and number of cells with DNA damage

Chi-square test, six and more cells: control vs. compensated and decompensated cirrhotic patients

Table 4. Degree of DNA damage in cells of controls, compensated cirrhotic patients and decompensated cirrhotic patients

\begin{tabular}{ccc}
\hline & \multicolumn{2}{c}{ Degree of DNA Damage } \\
\cline { 2 - 3 } Control & $5-40 \%$ Number of cells (\%) & \multicolumn{1}{c}{ (\%) Number of cells (\%) } \\
Compensated liver cirrhosis & $120(60 \%)$ & $60(86 \%)$ \\
Decompensated liver cirrhosis & $10(14 \%)$ & $124(95 \%)$ \\
\hline
\end{tabular}

The table shows the total number and percentage of cells with DNA damage by study group. Chi-square test, DNA damage degree $<40 \% \mathrm{P}<0.0001$, control vs. compensated and decompensated cirrhotic patients, Patients with compensated vs. decompensated cirrhosis, $\mathrm{P}<0.001$

\section{Discussion}

Alcohol acts in a varied manner and its association with growing oxidative stress with the formation of Free radicals and lipid per oxidation has been well documented. Available literature has demonstrated that chronic alcohol consumption is associated with an increase in the incidence of a variety of disease ranging from hepatitis to cancer [9]. It has been observed that high ethanol consumption results in oxidative damage, the process, which produces and accelerates pathogenesis and necrosis of liver. It has also been demonstrated that progression of disease from fibrosis to cirrhosis is due to accumulation of oxidative stress and genotoxicity. These changes are in congruence with our results to those occurring in hepatocellular carcinoma [17,18]. Oxidative stress has been attributed to cause serious liver damage and hepatic degeneration and responsible for worsening of patient condition on chronic alcohol ingestion [19,20].

On the other hand, it has been demonstrated that evaluation of DNA damage is considered as a good biological marker for oxidative stress. In this regard, some in vitro studies have revealed that chronic ethanol consumption increases DNA damage in lymphocytes, and that it is acetaldehyde, the product of ethanol metabolism, which is responsible for damage. Similarly, the mechanism proposed is enrooted through free radical generation $[21,22]$.

In terms of oxidative stress, results reported in the scientific literature are very much consistent with the finding that increased alcohol intake promotes lipid peroxidation and DNA damage and few studies have also noted that chronic ethanol consumption promotes cytochrome P 450 activity and increased rates of lipid per oxidation, and that there is greater damage to biomolecules in cirrhotic patients with continuous alcohol exposure in comparison with healthy adults $[17,18]$. In this regard, in or study we observed greater DNA damage in decompensated patients than with compensated cirrhotic patients with worsening patients condition.

The results obtained in the present study showed that the DNA damage frequency observed in adults with chronic alcoholism in decompensated $73 \%$ vs. compensated cirrhosis $42 \%(\mathrm{P}<0.01)$. Hence it appears imperative that with growing alcohol consumption there has been accumulation of oxidative stress leading to lipid peroxidation and DNA damage.

However observing mean total of DNA damage migration in these groups we note that for healthy adults $8.86 \mu \mathrm{m} \pm 2.58$ was found while for compensated cirrhosis we found $15.37 \mu \mathrm{m} \pm 1.34$, values that as previously indicated were lower than those for adults with decompensated cirrhosis, who demonstrated a value of $57.05 \mu \mathrm{m} \pm 5.22$. This allows us to propose that with increased alcohol consumption there is rise in oxidative stress, the fact that some authors report that DNA Damage increases with increase in oxidative stress and with exposure to alcohol and acetaldehyde $[21,22,23]$ It has been noted in decompensated cirrhosis patients that this damage presents gradually as the subjects advance with cirrhosis of liver which can be well collaborated with liver dysfunction; nevertheless, in alcoholics chronic exposure 
to alcohol provokes significant and lasting liver pathogenesis, propitiating a higher degree of DNA damage occurring with alcohol overexposure.

\section{Conclusion}

The results of the study corroborated to the fact that alcohol ingestion is a risk factor for DNA damage and progression of liver cirrhosis. The accumulation of oxidative stress determinants contribute to acceleration and conversion of liver fibrosis to cirrhosis which further worsens to advance stage of liver cirrhosis, and hepatocellular carcinoma.

\section{References}

[1] Abou-Seif, M., Rabia, A, and Nasr, M. Anti oxidant status. Erythrocyte membrane lipid peroxidation and osmotic fragility in malignant lymphoma patients. Clin Chem Lab Med 2000; 38: 73742.

[2] Dias-Da-Motta, p., Arruda, V.R., Muscara, M.n., Saad, T.O., De Nucci, G and Costa, F. The release of nitric oxide and superoxide anion by neutrophils and mononuclear cells from patients with sickle cell anemia. Br J Hem 1996; 93: 333-40.

[3] Ljubuncic, T., Tane, Z. and Bomzon, A. Evidence of a systemic phenomenon for oxidative stress in cholestatic liver disease. Gut 2000; 47: 710-6.

[4] Nalini,G., Hariprasad C. and Narayanan VA.Oxidative stress in alcoholic liver disease. Indian J Med Res 1999; 110: 200-3.

[5] Togashi, H., Shinzowa, H., Wakabayashi, H., Nakamura, T., Yamada, V., Takahashi, T. and Ishikawa, M. Activities of free oxygen radical scavenger enzymes in human liver. J Hepatol 1999; 11: 200-5.

[6] Brooks, P.J. DNA Damage, DNA repair, and alcohol toxicity a review. Alcoholism, Clinical \& Experimental Research. 1997; 21, 1073-1082.

[7] Friedman, SL. The cellular basis of hepatic fibrosis. Mechanism and treatment strategies. $N$ Engl J Med 1999; 328: 1828-35.

[8] Svegliati-Baroni, G., Di Sario, A., Casini, A., Ferretti, G., D” Ambrosio, L., Ridolfi, F., Bolognini, L., Salzano, R., Orlandi, F. and Benedetti, A. The $\mathrm{Na}+/ \mathrm{H}+$ Exchanger modulates the fibrogenic effect of oxidative stress in rat hapatitic stellate cells. $J$ Hepatol 1999; 30: 868-75.

[9] Sukamato, HC., Kim, W., Louz, Z., Horn, W and Sul, C. Role of Lipid peroxidation in vitro and in vivo models of liver fibrogenesis. Gastroenterology 1993; 104: 1012.
[10] Neelesh Deshpande, Sabitha Kandi, P Venkata Bharath Kumar, K V Ramana, and Manohar Muddeshwar, "Effect of Alcohol Consumption on Oxidative Stress Markers and its Role in the Pathogenesis and Progression of Liver Cirrhosis.” American Journal of Medical and Biological Research 1, no. 4 (2013): 99102. doi: 10. 12691/ajmbr-1-4-3.

[11] H. Sies. Strategies of antioxidant defence. Eur. J. Biochem. 1993; 215, 213-219.

[12] DIN Sherman R Williams, Liver damage: mechanisms and management, British Medical Bulletin (1994) Vol. 50, No.1; $124-$ 138.

[13] Poli, G. Liver damage due to free radicals. British Medical bulletin 1993; 49: 604-620.

[14] Ghany M, Hoofnagle JH. Liver and Biliary tract disease. In: Fauci AS, Kasper DL et.al editors. Harrison's Principles of Internal Medicine. $17^{\text {th }}$ ed. US: McGraw Hill; 2008; (2) P-1923.

[15] Gerard-Monnier D, Erdehneier I, Chandiere J, Yadan JC. Method of Colorimetric Analysis of Malondialdehyde and 4 Hydroxy-2Enaldehydes as indices of lipid peroxidation. 1998; patent Number: 5, 726, 063

[16] Singh, N.P., McCoy, M.T., Tice, R.R.et.al. (1988) A simple technique for quantitation of low levels of DNA damage in individual Cells. Experimental Cell Research 175, 184-191.

[17] Tsukamoto, H., Lu S. C. Current concepts in the pathogenesis of alcoholic liver injury. FASEB J. 2001; 15, 1335-1349.

[18] Wang, Y., Millonig, G., Nair, J., Patsenker, E., Stickel, F., Mueller S., Bartsch H., Seitz, HK. Ethanol-induced cytochrome P 4502 E 1 causes etheno-DNA lesions in alcoholic liver disease. Hepathology 2009; 50: 453-461.

[19] Hodges, NJ, Green RM., chipman JK., Graham M. Induction of DNA Strand Breaks and oxidative stress in Hela cells by ethanol is dependent on CYP 2 E 1 expression. Mutagenesis 2007; 22 (3): 189-194.

[20] Varga, M. How can free radicals cause damage to hepatic cells. A multidisciplinary approach. Drug and alcohol dependence 1991; 27: 117-119.

[21] Raquel Retana-Ugalde, Mario Altamirano-Lozano and Victor Manuel Mendoza-Nunez. Is there a similarity between DNA damage in adults with chronic alcoholism and communitydwelling healthy older adults Alcohol and alcoholism (2007), 42 (2): 64-69.

[22] Singh, N.P. and Khan, A.Acetaldehyde: genotoxicity and cytotoxicity in human lymphocytes. Mutation Research 1995; 337: 9-17.

[23] Román, J., Colell, A., Blasco, C., Caballeria, J., Pare's, A., Rode's, J., and Ferna'ndez-Checa, JC. Differiancial role of ethanol and acetaldehyde in the induction of oxidative stress in HEP G 2 cells: Effect on Transcription factors AP-1 and NF-kB. Hepatology 1999; 30: 1473-1480. 